\title{
La Literatura Infantil Iberoamericana, iesa gran desconocida?
}

\author{
JAIME GARCÍA PADRINO \\ Universidad Complutense de Madrid
}

\section{RESUMEN}

Es un hecho innegable que la Literatura Infantil y Juvenil haya adquirido en las últimas décadas un importante desarrollo en los distintos países de Iberoamérica, tal y como lo pone de manifiesto la ingente cantidad de publicaciones e investigaciones sobre la materia. En el presente trabajo se realiza un recorrido por el universo de la literatura infantil tanto en España como en Iberoamérica a través de su creación y principalmente de su difusión. Asimismo, se analizan los catálogos españoles de Literatura Infantil y Juvenil iberoamericana y se ofrece una perspectiva crítica sobre esta disciplina. Por último, el autor presenta una panorámica de la Literatura Infantil iberoamericana y un listado de referencias bibliográficas, que constituyen una aproximación al canon interdisciplinar - y también personal - en los distintos países del otro lado del Atlántico.

Palabras clave: Literatura Infantil y Juvenil iberoamericana, canon, referencias bibliográficas.

\section{ABSTRACT}

It's an undeniable fact that Children's and Youth Literature have acquired an important development in Latin American countries in the last decades, just like it reveals the big number of the publications and research about this subject. That work is a tour about the universe of children $s$ and youth Literature in Latin America offering a critical perspective about this subject. As well, it analyzes the spanish catalogues of Children's and Youth Literature and it offers a critical perspective about this. Finally, the author presents an overview of Children's Literature in Latin America and a list of bibliographic references that are an approach to interdisciplinary canon - even personal - in several countries on the other side of the Atlantic Ocean.

Keywords: Children's and Youth Literature, canon, bibliographic references.

Hoy por hoy, la literatura infantil y juvenil es una realidad sociocultural, económica y artística indiscutible, aún en los países con un desarrollo más reciente o más retardado para este tipo de creaciones literarias. Así lo avala el sinnúmero de actividades promotoras, formadoras, investigadoras y difusoras que se vienen realizando, de forma más concreta, en el mundo iberoamericano durante los últimos treinta años en torno a este tema general y en los más diversos ámbitos. A título de ejemplo mencionaré ahora la creación y funcionamiento de la Academia Latinoamericana de Literatura Infantil y Juvenil, fundada con el llamado Manifiesto de Ayacucho (Perú), firmado el 28 de junio de 2002 por representantes de Cuba, Perú y Uruguay, que constituyeron después las Comisiones Organizadoras de las respectivas Academias Nacionales, a las que se unieron después Bolivia y Ecuador,
Jaime García Padrino

Jaime García Padrino es catedrático de Didáctica de la Lengua y la Literatura. En la actualidad dirige el Departamento de Didáctica de la Lengua y la Literatura, de la Facultad de Educación, Centro de Formación del Profesorado, en la Universidad Complutense de Madrid.

Ha participado en distintos congresos y simposios nacionales e internacionales, con ponencias y comunicaciones dedicadas a los problemas de la biblioteca escolar, a la promoción y difusión de la literatura infantil, al papel de la literatura infantil en la educación para la paz, a los libros de texto y la lectura escolar, y al carácter de la literatura infantil, entre otros temas.
La Literatura Infantil

Iberoamericana,

¿esa gran desconocida?

JAIME GARCÍA PADRINO 
cerrando la constitución y aprobación de los estatutos generales en la reunión de Bolivia en el año 2009.

Pero, en ese completo y adecuado conocimiento o proyección social, precisamente, queda aún mucho camino por recorrer. Y a mejorarlo debemos dedicar los mejores y más rigurosos esfuerzos todos los que nos consideramos implicados en esa realidad de la relación de los más jóvenes con la Literatura.

En los últimos diez años, distintas circunstancias personales y actividades académicas me han permitido descubrir la riqueza y la variedad de las manifestaciones literarias en el mundo latinoamericano. Riqueza y variedad que arrancan desde sus más remotos orígenes, vinculados a la tradición oral de las comunidades prehispánicas, y vivificados posteriormente con los legados aportados por los colonizadores y sus respectivas culturas.

La particular evolución de cada uno de los países que conforman el ámbito latinoamericano durante los periodos anterior y posterior a su independencia de la metrópoli justifica, por otra parte, sus notables diferencias en la consolidación de la infancia y de la juventud como destinatarias literarias. Así hoy en este panorama global encontramos desde tradiciones literarias iniciadas ya en los finales del siglo xix, hasta aquellas que en las tres últimas décadas conocen un brotar firme y comienzan a perder el casi forzado vínculo con los intereses educativos del adulto hacia la infancia. Tales diferencias permiten, incluso, hablar de distintos niveles en el conjunto de la literatura infantil iberoamericana recurriendo para ello al concepto del ABC, utilizado por Joel Franz Rosell al ofrecer un panorama histórico de esta realidad literaria en el año 1995 (Peña Muñoz 28). Así, tendríamos un primer nivel de mayor desarrollo correspondiente a la A de Argentina. Con la B nos referimos a Brasil, de muy similar nivel, y con la C abarcaríamos países como Cuba, Colombia o Chile, donde el desarrollo ha sido también notable a partir de la segunda mitad del siglo pasado, y categoría donde podemos incluir sin reparo ya a otras literaturas nacionales, como la de México, Venezuela, Uruguay, Perú o Ecuador. Mientras, hay que alabar los esfuerzos realizados por otros países como Bolivia, República Dominicana, Costa Rica, Paraguay, o por Guatemala, Honduras, El Salvador y Nicaragua que conforman esa compleja realidad sociopolítica y económica de la América Central, sin desdeñar u olvidar el pujante avance de la cultura chicana en los Estados Unidos de América.

Sin embargo, cuando repasamos la presencia de obras y autores americanos en la actual oferta editorial al alcance de los lectores infantiles y juveniles españoles, no aparece suficientemente reflejada tan rica realidad. Esa limitada presencia parece difícil de entender cuando tales publicaciones aparecen con sellos editoriales consolidados ya en ambas orillas del Atlántico. Es decir, una determinada empresa editorial no ofrece los mismos títulos en sus colecciones según éstas aparezcan en España o en otro país iberoamericano. Si bien tal hecho pudiera comprenderse desde la lógica perspectiva de una libertad empresarial o desde el respeto o la deseable adecuación a unas realidades nacionales o culturales bien diferenciadas, no podemos evitar el temor de que tales diferencias se deban a una cierta paradoja: si bien el español o castellano es una lengua común para casi quinientos millones de hablantes y estudiada por más de catorce millones como lengua extranjera, sus variantes nacionales en léxico, sintaxis y giros coloquiales restan posibilidades de difusión más general a las obras dedicadas a los lectores más jóvenes, desde una discutible perspectiva adulta preocupada por el deseo de adaptarse a la realidad más concreta de estas edades.

\section{La literatura infantil en español a ambos lados del océano}

Dado que cualquier generalización siempre es peligrosa por ocultar, precisamente, hechos o realidades individuales de interés, debemos recordar la presencia en la evolución de la Literatura Infantil española de autores nacidos allá del Atlántico desde los primeros años del siglo xx y, al mismo tiempo y en sentido inverso, cómo las famosas publicaciones de la madrileña editorial Saturnino Calleja cruzaron el océano y conocieron allá una notable difusión entre los lectores infantiles iberoamericanos, debido, sin duda, al hecho de contar, desde finales del siglo XIX con una importante base en México para su difusión en el continente americano, en un claro precedente de la expansión desarrollada por nuestras editoriales actuales en los últimos treinta años. 
También hay que recordar casos reveladores de la presencia de autores iberoamericanos en la oferta editorial española como el de la chilena universal Gabriela Mistral, que publicó Ternuras. Canciones de niños (1924), con esa misma editorial Saturnino Calleja o la peruana Angélica Palma, con la editorial burgalesa Hijos de Santiago Rodríguez, Contando cuentos (1930).

Años después, con el movimiento migratorio impuesto a los españoles «transterrados» por el fin de la Guerra Civil, Antoniorrobles, Salvador Bartolozzi y Magda Donato, entre otros escritores, se establecían y continuaban su obra en México, mientras que Elena Fortún y el ilustrador Federico Ribas lo hacían en Argentina y Herminio Almendros impulsaba la educación y la literatura infantil en Cuba (Pelegrín, Sotomayor y Urdiales).

Sin pretender una enumeración exhaustiva de estos trasvases creativos, años más tarde las difíciles circunstancias de las dictaduras militares y las crisis económicas del llamado Cono Sur trajeron hasta España - de nuevo una mera enumeración a modo de ejemplo- al uruguayo Ricardo Alcántara, a los argentinos Ana Pelegrín y Jorge Werfelli - precedidos en el tiempo por Carmen Vázquez-Vigo-, a los chilenos $\mathrm{M}^{\mathrm{a}}$ Luz Uribe y Fernando Krahn, al peruano Carlos Villanes y tantos otros que, sin ser citados ahora, han colaborado de forma notable al auge de la Literatura Infantil en la España de los últimos treinta años.

\section{Conocimiento crítico y difusión de la Lite- ratura Infantil iberoamericana}

Pero debemos volver al punto de partida inicial: el insuficiente conocimiento global de esa realidad literaria dedicada a la infancia y a la juventud iberoamericana. Global o por encima de las diferencias o fronteras nacionales. En el último tercio del siglo xx hay que reconocer como muy meritoria la labor realizada por la española Carmen Bravo Villasante con su Historia y antología de la literatura infantil iberoamericana (1966, 1982, 1987), pero, desde entonces, el desarrollo del género exigía otro esfuerzo como el realizado por el chileno Manuel Peña Muñoz, con Habia una vez... en América (Literatura Infantil de América Latina) (1997), siguiendo con fidelidad las enseñanzas y consejos de la propia Bravo Villasante. Pero aún queda hueco para un trabajo colectivo que pudiese romper, poco a poco, con las lógicas diferencias nacionales, no mediante una hegemonía igualadora, sino por el mejor conocimiento de todas y cada una de esas diversidades.

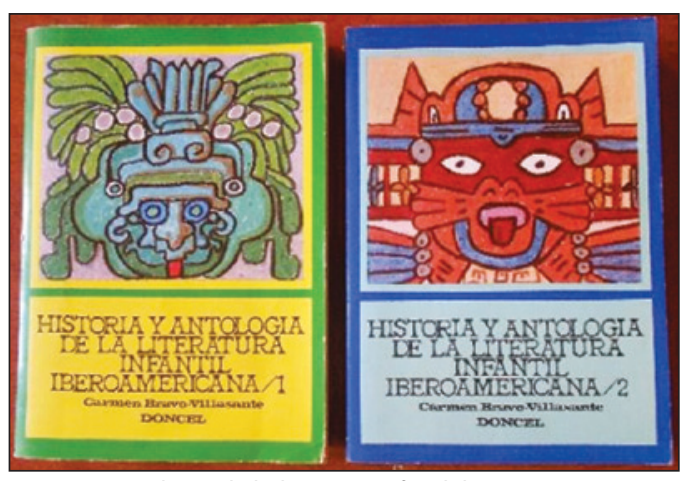

Historia y antología de la literatura infantil iberoamericana.

Unos años antes, Antonio Orlando Rodríguez ofrecía Panorama histórico de la literatura infantil en América Latina y el Caribe (1993), con el patrocinio del CERLALC. En esta obra, el autor abría ese panorama con una visión general de la importancia del folclore como origen de estas literaturas, pasando después a la literatura impresa en el siglo xIx, donde ubicaba, como era natural y obligado, La Edad de Oro (1889), de José Martí. Al entrar en el siglo xx, utilizaba una periodización por décadas $\mathrm{y}$, dentro de cada una de ellas, un breve apunte biográfico y crítico de los autores más representativos en opinión de Antonio Orlando Rodríguez, con la inclusión de textos extensos de algunas de las obras citadas y cerrando cada capítulo con una bibliografía de otras creaciones no citadas en el texto descriptivo.

\section{Catálogos españoles de literatura infantil iberoamericana}

Desde la orilla española contábamos con otra valiosa aportación a esa nueva mirada hacia la literatura infantil iberoamericana. Con el patrocinio de Acción Educativa y el claro impulso de Ana Pelegrín, aparecía un Catálogo de Literatura Iberoamericana Infantil y Juvenil (1999), con la colaboración de Nieves Martín Rogero, Graciela Pelegrín y Jesús Ángel Remacha, para desarrollar el siguiente objetivo: "Servir de recurso para el profesorado en la necesaria tarea del fomento de la lectura y, a la vez, difundir la obra de

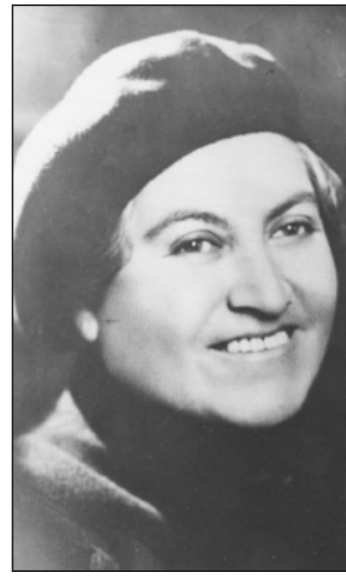

Gabriela Mistral.
La Literatura Infantil

Iberoamericana, ¿esa gran desconocida?

JAIME GARCÍA PADRINO 
autores iberoamericanos dirigida a la infancia y la juventud o accesible para estas edades».

Desde tal planteamiento el catálogo integraba «un conjunto de fichas sobre libros de autores iberoamericanos publicados en España desde 1973 hasta 1998». Además recogían también «libros de autores españoles que toman el continente sudamericano como temática o escenario en el que desarrollan sus historias», como medio para «fijar la recepción en España de la diversidad cultural latinoamericana». También señalaban que la estructura de las fichas tenía como modelo el utilizado por el Centro Internacional del Libro Infantil y Juvenil, en Salamanca, de la Fundación Germán Sánchez Ruipérez, además por agradecer la colaboración de distintas asociaciones y particulares en la cesión de libros para la elaboración de este catálogo.

Fue sin duda una interesante aportación si tenemos en cuenta las lógicas limitaciones de la institución que apoyaba esta iniciativa, Acción Educativa, como las derivadas del marco cronológico, los veinticinco años transcurridos desde 1973 a 1998, y, más en especial, el ocuparse exclusivamente de obras publicadas en España, criterio aceptable si lo que se pretendía, en primer lugar, era ofrecer un recurso para nuestro profesorado a la hora de fomentar la lectura entre sus alumnos.

Al revisar el índice de autores y países, quedaba clara esa particular clasificación antes citada del $A B C$ de la literatura iberoamericana, gracias a la abrumadora presencia de autores argentinos, no tan relevante la de brasileños, e importante también la de cubanos y chilenos, aunque con ausencias notables que deben atribuirse a su falta de ediciones españolas.

De tal forma el inicio del siglo actual mostraba la carencia de un trabajo colectivo, más amplio y riguroso en sus planteamientos y creado desde la propia realidad de aquel continente, donde pudiéramos encontrar una visión completa de la evolución histórica de la Literatura Infantil y Juvenil en Latinoaméri$\mathrm{ca}$, en forma de un diccionario biobibliográfico de autores. Así, al amparo del 27 Congreso del IBBY - celebrado en Cartagena de Indias (Colombia) en el año 2000-, la sección colombiana de este organismo internacional publicó Se hace camino... (Escritores e ilustradores del libro infantil y juvenil de los países latinoamericanos miembros del IBBY), donde eran también notable las diferencias entre tratamientos y presencias de los autores correspondientes a cada sección latinoamericana.

\section{El Premio Iberoamericano de Literatura Infantil SM}

Ya iniciado el presente siglo, la Fundación $\mathrm{SM}$, volcada con decisión a la realidad social y editorial del mundo latinoamericano, convocó en el año 2005 el Premio Iberoamericano SM de Literatura Infantil y Juvenil con la colaboración y patrocinio compartido del Centro Regional para el Fomento del Libro en América Latina y el Caribe (CERLALC), International Board on Books for Young People (IBBY), Organización de Estados Iberoamericanos para la Educación, la Ciencia y la Cultura (OEI), y la Oficina Regional de Educación para América Latina y el Caribe de la Organización de las Naciones Unidas para la Educación, la Ciencia y la Cultura (OREALC-UNESCO); con la colaboración de la Feria Internacional del Libro de Guadalajara (FIL), en cuyo marco se entrega anualmente el premio. Estas mismas instituciones designan a sus representantes en el Jurado encargado de resolver cada convocatoria para premiar, según sus bases, «los autores vivos que cuenten con una valiosa obra de creación para el público infantil y juvenil publicada, cuya importancia sea considerada de trascendencia para el ámbito iberoamericano y esté escrita en cualquiera de las lenguas que se hablan en Iberoamérica».

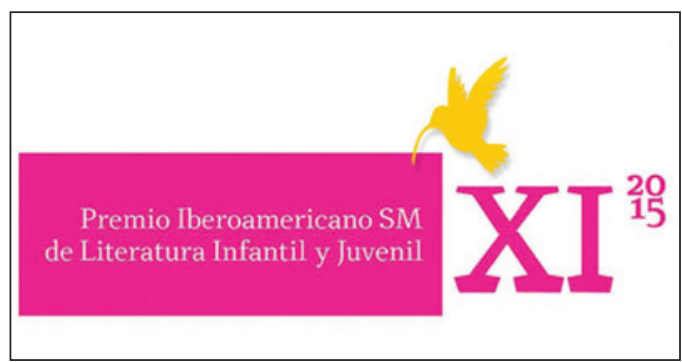

El Premio Iberoamericano de Literatura Infantil SM.

Transcurridas ya más diez convocatorias sería interesante comprobar la eficacia de tales premios en la difusión de los autores galardones dentro del ámbito latinoamericano. A modo de apunte, y dejando aparte los autores españoles premiados hasta el momento - Juan Farias, Montserrat del Amo, Jordi Sierra i Fabra y Agustín Fernández 
Paz-, en el caso de la colombiana Gloria Cecilia Díaz (Premio 2006), bien conocida antes del premio en las ediciones españolas, según la información del propio premio, su obra fue reeditada en nuestro país; la obra del brasileño Bartolomeu Campos de Queirós (Premio 2008) era prácticamente ignorada por las editoriales españoles y después del galardón, según los datos de la Agencia española del ISBN, sólo tiene una obra editada hasta el momento: Tiempo de vuelo (SM, 2009).

La ganadora de la convocatoria de 2009, María Teresa Andruetto, ha conocido una notable proyección tras su premio pues cuenta hasta el momento con seis títulos de carácter literario y dos de carácter didáctico. No tanta fortuna ha tenido Laura Devetach, quien después de haber conocido una edición de una de sus obras más difundidas en el ámbito americano Una caja llena (1984), sólo cuenta, según los datos de la Agencia Española del ISBN, con Avión que va, avión que llega: poemas para mandar en avioncitos de papel (Ediciones del Eclipse, 2007), dentro de la actual oferta editorial española.

Distinto es también el caso de Ana María Machado (ganadora del Premio 2012), ya muy bien conocida en España, incluso antes de su Premio Andersen 2000. Precisamente, esa condición había sido resaltada en convocatorias anteriores del Premio Iberoamaricano SM como mención de honor, hasta conseguir ese año ser considerada por el jurado correspondiente merecedora de este galardón.

Más aportaciones al conocimiento crítico y difusión de la Literatura Infantil iberoamericana

Mis intereses investigadores y académicos - volcados durante cerca de cuarenta años hacia la Literatura Infantil y Juvenil española, es decir, escrita originalmente en español y publicada en España - recibieron un importante estímulo con motivo de mi participación como jurado del Premio Iberoamericano de Literatura Infantil SM, en sus dos primeras convocatorias (2005 y 2006). Al revisar y estudiar las documentaciones presentadas y conocer así las obras más representativas de los autores candidatos, descubrí aspectos - para mí entonces inéditos - de la producción actual en los países latinoamericanos y comencé a pergeñar las posibilidades de una visión conjunta de las particulares evoluciones históricas de este género, las creaciones literarias dedicadas a la infancia y a la juventud, en el marco de esa otra realidad no menos compleja: el mundo ibero o latinoamericano.

El siguiente paso personal fue la coordinación de un número monográfico de la revista española Primeras Noticias de Literatura Infantil (Número 239, diciembre 2008), bajo el título «La Literatura Infantil en Iberoamérica», y con artículos de Alicia Salvi y Carlos Silveyra (Argentina), Manuel Peña Muñoz (Chile), Víctor Montoya y Gaby Vallejo (Solivia), Luis Cabrera Delgado (Cuba), Frieda Liliana Morales Barco (Centroamérica) y Sylvia Puentes de Oyenard (Uruguay). Número corto de colaboradores, impuesto por la extensión del monográfico, pero representativo de las diferentes peculiaridades dentro del marco general abarcado por el título citado del monográfico.

Entre las iniciativas desarrolladas en nuestro país dos proyectos de distinto planteamiento a la hora de difundir las obras de autores latinoamericanos coincidieron prácticamente en el tiempo. De un lado, la guía de lectura elaborada por el CEPLI, con la dirección de Santiago Yubero y Pedro C. Cerrillo, bajo el título De aquel lado del Atlántico. 75 libros latinoamericanos para lectores españoles (2009). Pese a la limitación numérica declarada en el título, hay que reconocer una notable amplitud en lo relacionado con el lugar de publicación, gracias, sin duda, a la colaboración de instituciones como el IBBY mexicano, el IBBY argentino, el Banco del Libro de Venezuela y la colombiana Fundalectura, teniendo como lógico resultado una significativa representación de lo anunciado en el título, con obras agrupadas por los niveles de lectura habituales en este tipo de catálogos, aunque con algunas ausencias o presencias discutibles y la limitación de un solo título por autor, bien difícil cuando se trata de autoras como Lygia Bojunga Nunes o María Elena Walsh.

La convocatoria del I Congreso de Literatura Infantil y Juvenil Latinoamericana, que tendría lugar en Santiago de Chile entre el 25 y el 29 de febrero de 2010, auspició la elaboración de un trabajo colectivo, bien amplio y riguroso en sus planteamientos, donde se pudiera ofrecer una visión completa de la evolución histórica de la Literatura Infantil y Juvenil en Latinoamérica, bajo la forma de
La Literatura Infantil

Iberoamericana,

¿esa gran desconocida?

JAIME GARCÍA PADRINO 
La diferencia entre número de colaboradores y número de países radicó en que, de una parte, fue muy difícil encontrar el adecuado o dispuesto a realizar el trabajo ofrecido (caso de la República Dominicana), mientras que en los países centroamericanos pareció además oportuno contar con la misma colaboradora, dado su amplio conocimiento de El Salvador Guatemala, Honduras y Nicaragua.
La Literatura Infantil

Iberoamericana,

¿esa gran desconocida?

JAIME GARCÍA PADRINO un diccionario biobibliográfico de autores. Tal proyecto - que tuve la gran fortuna de ser acogido con entusiasmo por José Luis Cortés, entonces director de proyectos en la Fundación SM, y por Leoncio Fernández, como Presidente de esa misma institución - no contaba con precedentes similares, salvo los comentados anteriormente.

El primer paso en su puesta en marcha -corría el mes de marzo de 2008- era la búsqueda de los distintos colaboradores que se encargarían, bajo mi coordinación, de seleccionar los autores -anteriores a 1850 y hasta el momento actual- a incluir en el Diccionario y de redactar las fichas correspondientes, junto con una breve introducción donde se contemplasen, de forma sucinta, los orígenes de estas creaciones literarias en cada país. Para tal selección-además de investigadores y expertos bien conocidos ya por sus trabajos y trayectorias en este campo-, solicitamos referencias y opiniones a instituciones representativas en determinados países. El resultado final de esa búsqueda y selección quedó reflejado en el conjunto de colaboradores -dieciséis para los veinte países ${ }^{1}$ - que hicieron posible la realización del proyecto, bien acreditados como investigadores latinoamericanos con amplia experiencia en el estudio y la difusión de la Literatura Infantil y Juvenil.

Estos colaboradores elaboraron las correspondientes propuestas nacionales con el criterio básico del carácter representativo de los diferentes autores, sin entrar en número mínimo de publicaciones, premios recibidos o cualquier otro tipo de méritos relevantes, y tratar de evitar así que ese Diccionario fuese un mero recopilatorio de autores con obra publicada, gracias una necesaria labor selectiva, que debía adaptarse, ante todo, a la realidad.

No obstante, como coordinador, era consciente del peligro habitual en este tipo de trabajos y que suele traducirse en la clásica frase «No están todos los que son, ni son todos los que están». Paradoja, a veces, de difícil solución o «al gusto de todos». Por otra parte, dado también el interés por implicar en cierto modo a instituciones representativas de los distintos países, se les hizo llegar para su conocimiento y consideración las iniciales propuestas nacionales con el ruego de que, en caso de estimarlo conveniente o necesario, realizasen sugerencias concretas a la hora de conseguir la más completa representación de autores latinoamericanos. Lo cierto es que, en tales consultas, no hubo motivos importantes de discrepancias, ni olvidos significativos, y todas las consideraciones enviadas fueron tan agradecidas como estimadas con interés por el coordinador y por los correspondientes colaboradores.

Completada esta primera fase del proyecto se elaboró, por parte del coordinador y con las sugerencias del editor, un modelo de ficha por autor, donde se deberían recoger las siguientes informaciones:

1) Biografía, con los datos esenciales de la trayectoria personal, académica y profesional de cada autor, su dedicación creadora y reconocimientos recibidos.

2) Obras representativas con un comentario crítico o, al menos, un breve resumen de sus contenidos. Dadas las evidentes diferencias en un elenco tan amplio como el considerado, pareció oportuno limitar las citas a un máximo de cinco. Para completar esas descripciones incluimos en cada ficha un máximo de otras diez obras o títulos, límite deseable para conseguir un cierto equilibro en los espacios dedicados a los distintos autores incluidos.

3) Comentario crítico de la aportación global del autor reseñado a la Literatura Infantil y Juvenil de su país y, por proyección, a la Literatura Infantil y Juvenil Iberoamericana. Importante y revelador apartado, pues se pretendía así que cualquier lector del Diccionario, no especializado en un autor o en un determinado país, pudiese tener una valiosa información a modo de referencia inicial para un posterior conocimiento más completa si así lo desea.

4) Como cierre de cada ficha, unas referencias bibliográficas con los libros, artículos y páginas webs que ofreciesen información relevante, críticas o interpretaciones de interés acerca del autor tratado.

Otra cuestión era el respeto a un tono personal, un estilo propio de cada redactor o colaborador. Por parte del coordinador, en la revisión de las fichas elaboradas, fueron respetadas esas lógicas diferencias en aras de 
una mayor riqueza en la expresión y en la amenidad de su lectura. Había que conjugar ese toque individual con el conjunto tan variado y complejo como este de más de novecientos autores de veinte países distintos para conseguir así otro de los grandes objetivos de este proyecto: ofrecer un panorama global respetando las distintas peculiaridades de la compleja realidad latinoamericana.

Como problema inherente a este tipo de trabajos, nada más presentar la obra ya editada el 27 de febrero de 2010 dentro de los actos de aquel inolvidable congreso de Santiago de Chile, éramos conscientes de que pedía ya una actualización para incorporar, lo antes posible, las novedades en obras y autores que se habían producido desde el cierre de la fase de redacción -31 de agosto de 2009-, como reflejo natural de la pujante vitalidad actual de estas creaciones literarias. Y esa vía sería posible por el nacimiento simultáneo de la edición en papel y de la edición electrónica, lo que permitiría -una vez establecidos los mecanismos internos para ello- incorporar tales novedades de forma mucho más ágil y eficaz que el tradicional formato libro, a la vez que ampliaría casi sin límite las posibilidades para su consulta o acceso a través de las nuevas tecnologías.

\section{Aproximación a una panorámica de la Lite- ratura Infantil iberoamericana}

Una primera, aunque superficial, aproximación a este florecimiento de la Literatura Infantil y Juvenil Iberoamericana permite apuntar algunos factores básicos en su desarrollo:

* de un lado, una libertad creadora que ha debido sortear en algunos momentos históricos una férrea censura política,

* la capacidad de superar las cortapisas de los condicionamientos editoriales marcados por la lógica rentabilidad económica o por unas rígidas estructuras sociales y educativas.

* Y de otro, la fuerte vinculación con unas extraordinarias raíces culturales, con una ancestral tradición oral carga$\mathrm{da}$ de leyendas y relatos estimuladores de la imaginación y de la fantasía, junto con el amor hacia un pasado y un mundo en riesgo de extinción.
Junto a ellos, y en un difícil equilibro, el juego - siempre en riesgo - entre instrucción y recreación que ha marcado no sólo la atención educativa hacia la Literatura Infantil y Juvenil, con la inclusión de esta materia en la formación de maestros y profesores, sino también la ac-

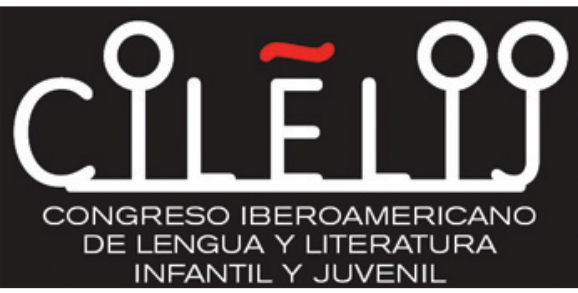

Congreso Iberoamericano de Lengua y Literatura Infantil y Juvenil. titud de muchos creadores a la hora de encarar su personal relación con estos destinatarios.

Por último, y contemplado este rico panorama desde esta orilla del Atlántico, surge la evidente paradoja ya aludida al principio de estas líneas cuando muchas de las ediciones aparecidas aquí y allá se enfrentan a una sutil, pero a veces impenetrable, barrera que impide su difusión en uno y en otro lado: la propia riqueza del español como idioma plagado de variantes nacionales, de vocabularios y giros autóctonos, que - casi siempre más desde el prisma de una visión adulta, no sé si timorata o proteccionista en exceso- se consideran entorpecedores de una fluida comprensión para los lectores de los otros países iberoamericanos, mientras se admiten sin trabas o rubores anglicismos impuestos por la fuerza de los nuevos medios de comunicación y difusión. Ante esta realidad, solo cabe la esperanza de que, poco a poco, un mejor conocimiento de esas realidades específicas entre los expertos, los creadores y los educadores que compartimos una misma lengua sea el mejor aliado a la hora de derribar tan sutil barrera y de conseguir con ello un mayor enriquecimiento de la realidad latinoamericana.

Las referencias bibliográficas incluidas en este artículo, así como cualquier selección crítica de obras literarias y de sus autores, siempre necesitarán una actualización después del momento de elaboración de esos listados y orientados, además, por el gusto o criterio personal de sus seleccionadores. Tal salvedad es oportuna para el listado que presento a continuación bajo el título de «Hacia un canon personal de la LIJ iberoamericana», a modo de recomendaciones personales o subjetivas con respecto a autores y obras que, en mi opinión, merecen un mejor conocimiento en nuestro país.

Para poner punto final a estas consideraciones, sólo me queda manifestar mi deseo y mi esperanza de que iniciativas como esta pu-
La Literatura Infantil

Iberoamericana, ¿esa gran desconocida?

JAIME GARCÍA PADRINO 
blicación o cualquier otra actividad académica puedan contribuir a un mejor conocimiento de la extraordinaria riqueza de la literatura infantil y juvenil escrita en español a ambos lados del Océano Atlántico.

Un canon personal de la LIJ iberoamericana:

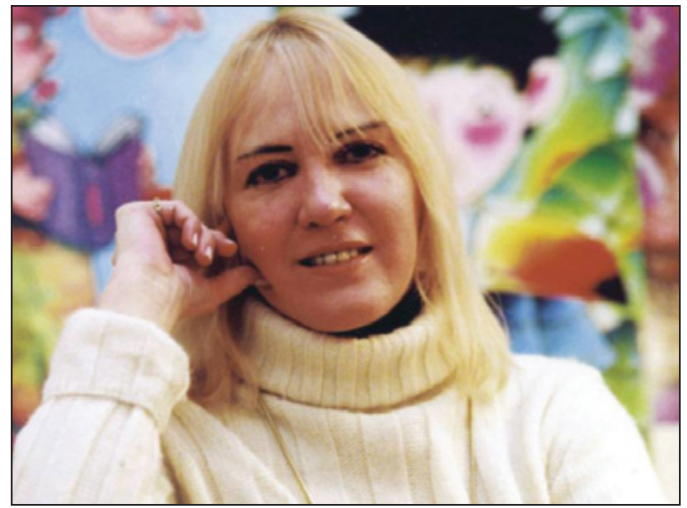

Elsa Bornemann.

\section{Argentina}

Bornemann, Elsa. No hagan olas (Segundo pavotario ilustrado. 12 cuentos). Il. de O'Kif. Buenos Aires: irrompibles (Cuentos de los chicos enamorados). Il. de Guido Bruveris. Buenos Aires: Librerías Fausto, 1981.

Bornemann, Elsa. Un elefante Alfaguara, 1993.

Bornemann, Elsa. No somos ocupa mucho espacio. Buenos Aires: Alfaguara, 2004. (Edic. digital: Il. de Mónica Pironio. Buenos Aires: Ministerio de Educación/Plan de Lectura, 2013).

Cabal, Graciela Beatriz. Cosquillas en el ombligo. Il. de Nora Hilb. Buenos Aires: Sudamericana, 1990.

Cabal, Graciela Beatriz. La pandilla del ángel. Il. de Daniel Rabanal. Buenos Aires: Aique, 1994.

Montes, Graciela. Betina, la máquina del tiempo. Il. de Elena Torres. Madrid: Cincel, 1984.

Montes, Graciela. La batalla de los monstruos y las hadas. Il. de Ximena de Maier Pan de Soraluce. Madrid: Alfaguara, 2005.

Walsh, María Elena. El Reino del Revés. Buenos Aires: Luis Fariña Editor, 1965. ( $2^{a}$ edic.: Il. de Nora Hilb. Madrid: Santillana, 2001).

Walsh, María Elena. Tutú Marambá. Il. de Chacha. Buenos Aires: Luis Fariña Editor, 1965.

Wolf, Ema. Barbanegra y los buñuelos. Il. de Sergio Kern. Madrid: Cincel, 1984.

Wolf, Ema. El fantasma de la tía Maruja. Il. de la autora. Madrid: Montena, 2007.

a Literatura Infantil

Iberoamericana,

¿esa gran desconocida?

JAIME GARCÍA PADRINO

\section{Brasil}

Bojunga Nunes, Lygia. La cuerda floja. Il. de Arcadio Lobato. Madrid: Alfaguara, 1981.
Bojunga Nunes, Lygia. La casa de la madrina. Il. de Arcadio Lobato. Madrid: Alfaguara, 1983.

Machado, Ana María. Algunos miedos. Il. de Agustín Comotto. Madrid: Anaya, 2005.

Machado, Ana María. El domador de monstruos. Il. de María Luisa Torcida. Madrid: SM, 1996.

Machado, Ana María. La abuelita aventurera. Il. de Pablo Núñez. Madrid: SM, 1992.

Vasconcelos, José Mauro de Corazón de vidrio. Il. del autor y de Gioconda Uliana Campos. Buenos Aires: El Ateneo, 1976.

Vasconcelos, José Mauro de. Mi planta de naranja-lima. Buenos Aires: El Ateneo, 1996.

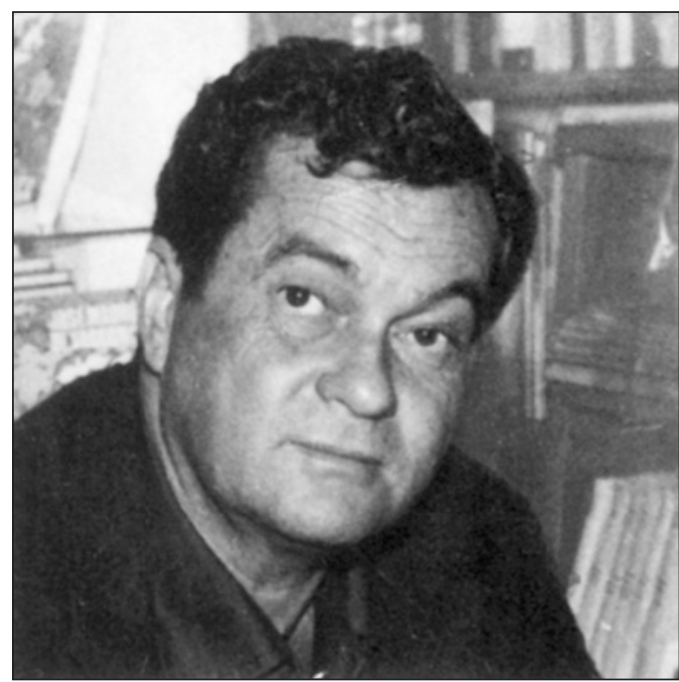

José Mauro de Vasconcelos.

\section{Bolivia}

Guzmán Soriano, Rosalba. Conquistando a Lindolfo. Il. de Jorge Dávalos. La Paz (Bolivia): Alfaguara, 2008.

Méndez, Mario. Cabo Fantasma. Una historia de piratas. Il. de Shula Goldman. La Paz (Bolivia): Santillana, 2008.

Méndez, Mario. Pedro y los lobos. Il. de Elena Hadida. La Paz (Bolivia): Alfaguara, 2008.

Mesa de Inchauste, Isabel. El espejo de los sueños. Il. de Alejandro Salazar. La Paz (Bolivia): Santillana, 5a ed., 2009.

Mesa de Inchauste, Isabel. La pluma de Miguel. Il. de Guiomar Mesa. La Paz (Bolivia): Gisbert y Cía, 2008.

Mesa de Inchauste, Isabel. La portada mágica. Il. de Rosario Ostria. La Paz (Bolivia): Santillana, $6^{a}$ ed., 2009. 
Mesa de Inchauste, Isabel. La turquesa y el sol. Una historia de incas y chiriguanos. Il. de Guiomar Mesa y Alejandro Salazar. La Paz (Bolivia): Santillana, $3^{a}$ ed., 2007.

Vallejo Canedo, Gaby. Amor de colibrí. Il. de Ximena Claure. Cochabamba (Bolivia): edición de la autora, 1995.

Vallejo Canedo, Gaby. Castigado. Il. De Tania Maldonado. Cochabamba (Bolivia): edición de la autora, 2008.

\section{Chile}

Carvajal, Víctor. Cuentatrapos. Il. de Fuencisla del Amo. Madrid: SM, 1985.

Carvajal, Víctor. La balserita. Il. de Carolina Schütte. Santiago de Chile: Alfaguara, 2009.

Carvajal, Víctor. La pequeña Chonek. Il. de Alberto Montt. Santiago de Chile: Sol y Luna, 2008.

Gallegos, Manuel. Cuentos mapuches del Lago Escondido. Santiago de Chile: ZigZag, 2009.

Gallegos Manuel. Cuentos para no cortar. Il. de Andrés Julián. Santiago de Chile: MN Editorial, 2009.

Morel, Alicia. La Hormiguita Cantora y el Duende Melodía. Il. de Elena Poirier. Santiago de Chile: Zigzag, 24. ${ }^{\text {a }}$ ed. 2005.

Morel, Alicia. El secreto del caracol. Il. de Andrés Julián. Santiago de Chile: SM, 2010.

Paz, Marcela. Cuentos para contar. Il. de Marta Carrasco. Santiago de Chile: Universitaria, 1993.

Paz, Marcela. Papelucho. (Edición facsímil, Santiago de Chile: Rapa-Nui, 1947). Il. de Yola. Santiago de Chile: Ediciones Marcela Paz, 2009.

Peña Muñoz, Manuel. De la A a la Z: Chile. Il. de Soledad Sebastián Ortega. León: Everest: 2012.

Peña Muñoz, Manuel. Mágico Sur. Madrid: SM, 1997.

\section{Colombia}

Coll, Ivar da. Carlos. Il. del autor. Bogotá: Alfaguara, 1999.

Coll, Ivar da. Chigüiro y el lápiz. Il. del autor. Bogotá: Norma, 1985.

Coll, Ivar da. Pies para la princesa. Il. del autor. Madrid: SM, 2002.

Díaz, Gloria Cecilia. Óyeme con los ojos. Il. de Chata Lucini. Madrid: Anaya, 2000.

Díaz, Gloria Cecilia. El sol de los venados. Madrid: SM, 1993.

España, Gonzalo. La canción de la flor. Bogotá: Panamericana, 1996.

España, Gonzalo. Historias de amores y desvarios en América. Il. de Javier Fernando Porras. Bogotá: Panamericana, 1999.

Linares, Verónica. Clemencia, la vaca que quería ser blanca. Il. de Mario Burgos. Bogotá: Norma, 2003.

Linares, Verónica. Zacarías. Il. de Jorge Butrón. Bogotá: Norma, 2007.

Reyes, Yolanda. El terror de Sexto B. Il. de Daniel Rabanal. Bogotá: Santillana, 1995.

Reyes, Yolanda. Una cama para tres. Il. de Ivar da Coll. Bogotá: Alfaguara, 2007.

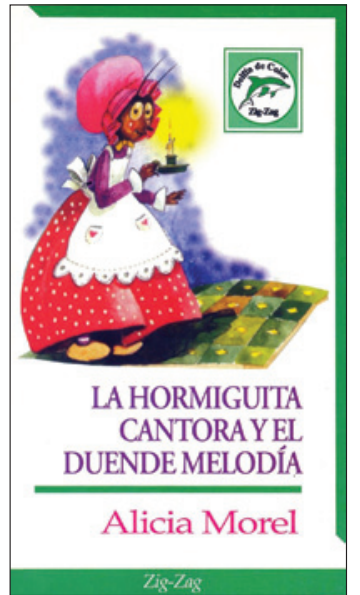

La Hormiguita Cantora y el Duende Melodía.
Cuba

Almendros, Herminio. Habia una vez... Il. de Bladimir González. La Habana: Gente Nueva, $12^{\mathrm{a}}$ ed, 1998.

Almendros, Herminio. Oros viejos. Il. de Jorge L. Fuentes Rodríguez. La Habana: Pueblo y Educación, 1990.

Alonso, Dora. El valle de la Pájara Pinta. Il. de Manuel González. La Habana: Gente Nueva, 1992.

Alonso, Dora. Ponolani. Portada de José Luis Posada. La Habana: Gente Nueva, $2^{a}$ ed., 1994.

Cabrera Delgado, Luis. El misterio del pabellón exagonal. La Habana (Cuba); Gente Nueva, 2008.

Cabrera Delgado, Luis. Mis dos abuelos. Santa Clara (Cuba): Capiro, 1992.

Cabrera Delgado, Luis. Querida Zoelia. Pról. de Joel Franz Rosell. Santa Clara (Cuba): Capiro, 2009.

Cardoso, Onelio Jorge. Caballito blanco. Il. de Horacio Elena. Santa Marta de Tormes (Salamanca): Lóguez, 1987.

Cardoso, Onelio. Negrita. Il. de Horacio Elena. Santa Marta de Tormes (Salamanca): Lóguez, 1985.

Martí, José. Cuentos de la Edad de Oro. Prólogo de Ferran Zurriaga. Il. de Manuel Boix. Barcelona: Laia, 1981.

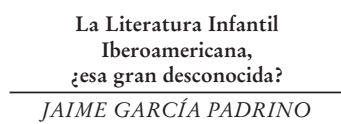




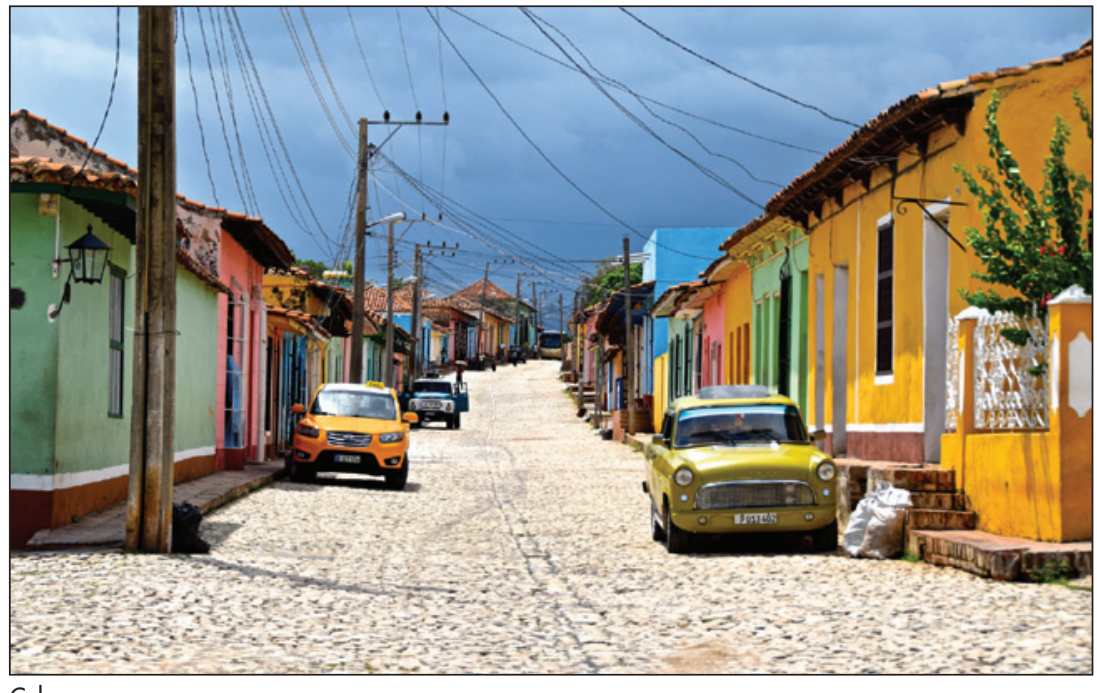

Cuba.
Martí, José. La Edad de Oro. Intr. de Gastón Baqueiro. Madrid: Mondadori España, 1990.

Perera, Hilda. El burrito que quería ser azul. Il. de Julia Díaz. León: Everest, 1992.

Perera, Hilda. Tomasín y el Cerdito. Il. de José Pérez Montero. León: Everest, 1992.

Pérez Díaz, Enrique. Desván de América: cuentos, leyendas, mitos, poemas, nanas, adivinanzas, retábilas, trabalenguas, fábulas, refranes y canciones de América para niños. Madrid: Miraguano, 2007.

Pérez Díaz, Enrique. Las cartas de Alain. Il. de Francisco Solé. Madrid: Anaya, 2011.

Prieto, Iliana: Cuentos de fantasmas, brujas $y$ otros bichos inofensivos. Il. de Miriam González. La Habana: Gente Nueva, 1999.

Rosell, Joel Franz: La bruja de La Habana Vieja. Il. de Amilkar Chacón. Santa Clara (Cuba): Capiro, 1999.

Saldaña, Excilia: La lechuza y el sijú. Il. de Luis Castro Enjamio. La Habana: Gente Nueva, 2002.

\section{Ecuador}

Bravo, Leonor. Viaje por el país del sol. Un recorrido mágico por el Ecuador. Quito: Alfaguara, 2003.
Bravo, Leonor. Encuentros inquietantes. Quito: Alfaguara, 2010.

Córdova, Leonor. ;Estoy harta de todos! Il. de Wylo Ayllón. Quito (Ecuador): El Tucán, 2008.

Heredia, María Fernanda: Por si no te lo be dicho. Il. de la autora. Quito (Ecuador): Santillana, 2003.

Iturralde, Edna. ...Y su corazón escapó para convertirse en pájaro. Il. de Santiago González. México: Alfaguara, 2001.

Iturralde, Edna. Cuando callaron las armas. Il. de Olga Lucía Aldana. Bogotá: Norma, 2007.

Iturralde, Edna. Entre cóndor y león. Il. varios. Quito (Ecuador): Alfaguara, 2007.

Iturralde, Edna. Verde fue mi selva. Il. varios. Quito (Ecuador): Alfaguara, 2009.

\section{México}

Carballido, Emilio. El pizarrón encantado. Il. de Iker Vicente. México D. F.: Santillana, 2004.

Dreser, Elena. Mi abuela tiene diez años. Il. de Alma Pacheco. México D. F.: CNCA, Direc. Gral. De Publicaciones, 2008.

Hinojosa, Francisco. A golpe de calcetín. Il. de Francisco González. México D. F: SEP, 1986.

Hinojosa, Francisco. La peor señora del mundo. Il. de Rafael Barajas «el fisgón». México D. F.: FCE, 8a reimp., 2002.

Murguía, Verónica. Auliya. México D. F.: Ediciones Era, 2005.

Sandoval, Jaime Alfonso. República mutante. México D. F.: SM, $1^{a}$ reimp., 2004.

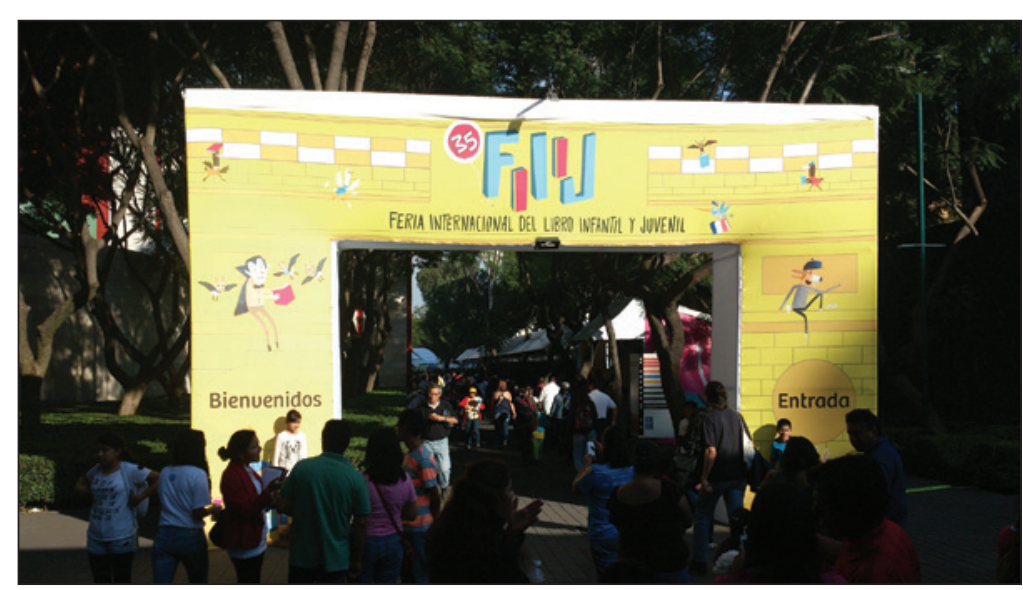

FILIJ, México. 


\section{Perú}

Alegría, Ciro. Fábulas y leyendas americanas. Edic. de Dora Varona. Il. de Horacio Elena. Madrid. Espasa-Calpe, 1982.

Alegría, Ciro. Sueño y verdad de América. Portada de Antonio Cobos. Madrid: Alfaguara, 1984.

Montalván Arteta, Sara. Siete cuentos para la semana. Il. de Antonio Ahumada. Santiago de Chile: MN, 2009.

Villanes Cairo, Carlos. Las ballenas cautivas. Il. de Esperanza León Jiménez. Madrid: SM, 1991.

Villanes Cairo, Carlos. Los dioses tutelares de los Wankas. Mitos y leyendas peruanos. Lima: San Marcos, 2006.

\section{Uruguay}

Amorín, Isabel. El arcón viajero. Vivencias en Colonia del Sacramento. Montevideo: Fin de Siglo, 2006.

Amorín, Isabel. El Éxodo. Juegos, peligros y sueños. Montevideo: Fin de Siglo, 2006.

Correa, Federico. El último enigma. Il. de Ana María Dolder. Montevideo: AULIAmphion, 2009.

Puentes de Oyenard, Sylvia. Un día con los abuelos. Il. de Ana María Dolder. Montevideo: AULI, 2007.

\section{Venezuela}

Nazoa, Aquiles. El perro, el chivo y los tigres. Caracas: Ekaré/Banco del Libro, 1982.

Nazoa, Aquiles. La niña, el pozo, el gato, el cojin bailador y las siete piedritas. Caracas: María di Mase, 1985.
Vannini, Marisa. El chigüire fantasma. Il. de Nieves Barceló. Caracas: El Nacional, 2004.

Vannini, Marisa. Ellos también descubrieron el Nuevo Mundo. Il. de Marcela Cabrera. Caracas: Playco, 2002.

\section{USA}

Ada, Alma Flor y F. Isabel Campoy. Cuentos que contaban nuestras abuelas. Cuentos populares hispánicos. Il. varios. New York: Atheneum, 2006.

Ada, Alma Flor y F. Isabel Campoy. Merry Navidad! Villancicos en español e inglés. Christmats Carols in Spanish and English. English versión de Rosalma Zubizarreta. Il. de Viví Escrivá. New York: Harper Collins, 2007.

\section{Referencias bibliográficas}

Pelegrín, Ana, María Victoria Sotomayor y Alberto Urdiales (edits.). Pequeña memoria recobrada. Libros infantiles del exilio del 39. Madrid: MEPSYD, 2008.

Peña Muñoz, Manuel. Historia de la Literatura Infantil en América Latina. Madrid: Fundación SM, 2009, p. 28.

Rosell, Joel Franz. «La literatura infantil latinoamericana. Una hoja de vida». Revista Latinoamericana de Literatura Infantil y Juvenil, núm. 2, Bogotá, julio-diciembre 1995.

Fecha de recepción: 01/06/2015

Fecha de aceptación: 15/10/2015 